\title{
O suicídio de escravos em São Paulo nas últimas duas décadas da escravidão
}

\section{The suicide of slaves in São Paulo during the last two decades of slavery}

Saulo Veiga Oliveira

Mestre em Ciências Biomédicas/ Faculdade de Ciências Médicas da Universidade Estadual de Campinas (FCM Unicamp). Rua Presidente Prudente, 420/31 Jardim Alto da Barra 13090-820 Campinas - SP - Brasil sauveiga@yahoo.com.br

\section{Ana Maria Galdini Raimundo Oda \\ Pesquisadora da Faculdade de Ciências Médicas da Universidade Estadual de Campinas Caixa Postal, 2135 Sousas \\ 13106-970 Campinas - SP - Brasil anaoda@uol.com.br}

Recebido para publicação em julho de 2007. Aprovado para publicação em setembro de 2007.
OLIVEIRA, Saulo Veiga; ODA, Ana Maria Galdini Raimundo. O suicídio de escravos em São Paulo nas últimas duas décadas da escravidão. História, Ciências, Saúde - Manguinhos, Rio de Janeiro, v.15, n.2, p.371-388, abr.-jun. 2008.

\section{Resumo}

A partir de notícias da Gazeta de Campinas (1871-1887), abordam-se visões correntes sobre atos suicidas entre cativos e pessoas livres, na província de São Paulo, assim como discutem-se os dados obtidos. Concluise que, sendo os atos suicidas manifestações humanas irredutíveis a um único tipo de explicação, não parece justificável que entre escravos eles sejam ainda tomados como autoexplicáveis por sua mísera condição. Ao indicar as situações em que se deram tais atos, espera-se desfazer explicações simplificadoras, como aquelas que referem os suicídios de escravos apenas e obviamente devidos aos 'desgostos do cativeiro'.

Palavras-chave: suicídio de escravos; província de São Paulo (Brasil); Campinas (SP); século XIX; Gazeta de Campinas.

\section{Abstract}

News stories printed in Gazeta de Campinas (1871-1887) are used to investigate the views expressed at the time of the suicides of captives and freedmen in São Paulo province, and to discuss the data available. As suicide is a form of human behavior which cannot be reduced to one single explanation, it does not seem justifiable that amongst the slaves, these cases should also be taken as selfexplanatory because of the conditions in which they occurred. By noting the circumstances in which these acts took place, it is hoped that the fallacy of oversimplified explanations can be belied, which refer to the suicide of slaves as quite simply being due to a 'dislike of captivity'.

Keywords: suicide of slaves; São Paulo province (Brazil); Campinas (SP); $19^{\text {th }}$ century; Gazeta de Campinas. 
$\mathrm{T}$ udo indica que o escravo Ambrósio estava decidido a viver em liberdade, a todo custo. Ao fugir da casa de seus proprietários, negociantes da cidade de Campinas, matou o empregado que experimentou impedi-lo. Sendo alcançado em Sorocaba, novamente deu cabo de um dos que tentavam reconduzi-lo ao estado de cativeiro. Condenado e preso, logo escapou, colocando em alerta aqueles que o temiam circulando, pois ele jurara várias pessoas de morte. Apanhado em Botucatu, foi reconduzido à cadeia de Campinas. Tal foi o rebuliço causado por esse escravo, que ele foi mencionado entre as ocorrências criminais notáveis do ano de 1873, no relatório do chefe de polícia Joaquim José do Amaral (São Paulo, 1874, p.10), que observava ter "felizmente" sido recapturado o perigoso preto.

Durante pouco tempo, porém, o temível escravo cumpriria sua pena de prisão com "ferro ao pescoço", referente a dois homicídios e uma tentativa de homicídio. Em 12 de outubro de 1874, depois de tentar várias vezes matar-se na cadeia, ele conseguiu, com um profundo golpe de faca no pescoço, realizar seu "desastrado intento", nas palavras do jornal local (Gazeta de Campinas" 15 out. 1874) que noticiou seu suicídio.

O caso de Ambrósio não é único, encontrando-se em notícias de jornais e nos relatórios de chefes de polícia da província outras histórias com final semelhante, de escravos condenados por homicídios que se mataram na prisão ou de escravos em fuga que preferiram a morte à prisão ou à volta ao cativeiro. Essa, porém, parece ter sido apenas uma das possíveis trajetórias seguidas pelos escravos e escravas que puseram termo a seus dias nas últimas duas décadas de escravidão na província de São Paulo e, em particular, no município de Campinas. É o que pretendemos indicar neste artigo, apresentando os resultados de pesquisa realizada em documentos editados entre 1870 e 1888, a folha noticiosa Gazeta de Campinas e as estatísticas policiais da província de São Paulo. ${ }^{2}$

\section{O suicídio de escravos na historiografia brasileira}

Ainda que se afirme serem muitos os casos de suicídios entre escravos, esse não é um ponto estudado detalhadamente. Se, como observou Ângela Porto (dez. 2006, p.10191027), questões referentes a saúde ou doenças dos escravos só têm sido entrevistas pelas 'frestas da história', com relação aos atos suicidas dos cativos ainda menos se tem vislumbrado. Na história da escravidão, o suicídio é quase sempre citado de passagem, em geral acompanhando comentários genéricos sobre formação de quilombos, fugas, homicídios e outras ações violentas que expressariam a rebeldia ou meios de negociação dos cativos, e raramente recebeu tratamento pormenorizado.

Os relatos de vários estrangeiros que observaram a escravidão no Brasil do século XIX mencionam que o suicídio era prática muito comum dos escravos. As mortes voluntárias entre os cativos são descritas tanto na forma passiva de recusar alimento e deixar-se morrer de tristeza, como no banzo, quanto na forma ativa - por enforcamento, afogamento, uso de armas brancas etc. Geralmente o desinteresse pela vida, a apatia extrema e o desejo de morrer são atribuídos, pelos narradores, a reações nostálgicas decorrentes da perda da liberdade e dos vínculos com a terra e grupo social de origem, e ainda aos castigos excessivos impostos pelos senhores. ${ }^{3}$ 
A descrição clássica do banzo parece ter sua origem no texto do ilustrado luso-brasileiro Luis Antonio de Oliveira Mendes, redigido em 1793 e publicado em 1812, Memória a respeito dos escravos e tráfico da escravatura entre a costa d'África e o Brasil (Oliveira Mendes, 1977; Oliveira Mendes 1983). Embora nem sempre haja citação explícita da fonte, ecos de sua descrição podem ser encontrados em alguns escritos de estrangeiros que estiveram no país na primeira metade do século XIX, repetidos em estudos subseqüentes (Oda, 2007). ${ }^{4}$

Contemporaneamente, poucos autores se ocuparam do suicídio de escravos de forma mais detalhada. Entre eles está Roger Bastide (1943), em estudo realizado quando professor da cadeira de sociologia da Universidade de São Paulo. Ainda que sua intenção principal seja particularizar o estudo das relações entre cor e suicídio em São Paulo, faz, no início desse trabalho, revisão histórica do suicídio entre escravos no Brasil, a partir dos relatos dos viajantes e da literatura antropológica sobre a África. Para a província de São Paulo, usa principalmente as informações (de 1870 a 1904) compiladas por Alcântara Machado, que as retirou dos relatórios dos chefes de polícia. Para Bastide, o suicídio dos cativos seria principalmente um protesto contra a escravidão, meio de se libertar de uma vida de castigos; ou seria decorrente das saudades da terra natal (p.2). Destaca ainda que, a despeito da concordância entre os vários povos do continente africano na condenação moral do suicídio, na situação de escravidão a crença em reencarnação com retorno à terra natal poderia justificar a morte voluntária, ponto que retomará no livro O candomblé da Bahia (Bastide, 2001, p.73).

José Alípio Goulart (1972, p.123-130) dedicou ao tema um capítulo de seu livro Da fuga ao suicídio, considerando-o a mais trágica das reações à violência do cativeiro. Para ele, o suicídio seria uma forma de fuga e também espécie de protesto e rebeldia, de vingança contra o senhor. Em sua análise, suicídios, homicídios e fugas eram reações decorrentes da inconformidade com o estado de escravidão e da impotência em modificá-lo. Em certos casos, o suicídio seria relacionado ao banzo e facilitado pela crença que teriam os negros no retorno espiritual à África. Goulart utiliza como fontes principais algumas estatísticas policiais e informações retiradas dos relatórios dos presidentes de diversas províncias brasileiras, além dos clássicos viajantes.

Em Dicionário da escravidão negra no Brasil, de Clóvis Moura (2004), o suicídio é definido como "uma das reações extremas de protesto do escravo" (p.381). Na redação do verbete, Moura baseia-se principalmente no trabalho de Goulart (1972), enfatizando a ocorrência de suicídios após a aplicação de castigos torturantes, bem como sua manifestação freqüente em todo o país. O banzo é ali definido como "estado de depressão psicológica que se apossava do africano logo após seu desembarque no Brasil. Geralmente os que caíam nessa situação de nostalgia profunda terminavam morrendo" (p.63), sendo longamente citado o já referido ensaio de Oliveira Mendes.

Em 1990, Renato Pinto Venâncio publicou breve artigo sobre o suicídio de escravos na cidade do Rio de Janeiro nas últimas duas décadas da escravidão, procurando correlacionar o fim do regime escravista ao declínio observado no número global de suicídios registrados. O autor usa os dados compilados pelo jurista Francisco Viveiros de Castro (também citado por Bastide, 1943), que em 1894 publicou um estudo sobre o suicídio na capital federal e por sua vez utilizou relatórios dos chefes de polícia editados entre 1870 e 1881 . Venâncio (1990) indica que o percentual de suicídios de escravos teria sido o dobro daquele dos livres 
e que as causas mais comumente atribuídas aos atos seriam "temor de castigo", "para evitar venda" e "maus-tratos", sendo a maior parte dos motivos ignorada. É apontada pelo autor a necessidade de aprofundar as pesquisas e estudar a distribuição dos suicídios segundo sexo, meios usados e etnias africanas envolvidas.

Em razão de sua originalidade e alcance, a interlocução com o trabalho de Mary Karasch (2001) torna-se obrigatória nos estudos sobre esse tema. Em seu amplo estudo sobre a vida dos escravos no Rio de Janeiro da primeira metade do século XIX, publicado em inglês em 1987 e em português em 2000, Karasch dedica ao suicídio uma das seções do capítulo sobre "fugitivos e rebeldes", usando como fontes vários relatos de viajantes, estatísticas policiais, registros hospitalares, correspondências oficiais, livros de óbitos e ainda o compêndio sobre as doenças do Brasil publicado em 1844 pelo doutor Sigaud, médico francês radicado no Rio.

Em amostra de 69 cativos, obtida de fontes variadas, a autora identificou como métodos mais comuns para os suicídios o afogamento, enforcamento ou estrangulamento e o uso de armas de fogo ou brancas. Karasch (2001) levanta e comenta o que considera as principais motivações para os suicídios: rebeldia contra a condição cativa e conseqüência dos maustratos; a nostalgia chamada de banzo e outras perturbações mentais graves; e desejo de retorno espiritual à África. Quanto ao último ponto, procura estabelecer conexões entre as crenças religiosas de grupos étnicos africanos mais presentes no Rio de Janeiro da época (como os ali chamados de congos, oriundos do centro-oeste africano) e o uso de métodos de suicídio como enforcamento ou afogamento, que facilitariam a desejada viagem espiritual à terra natal (p.244-246; 415-420; 497-503; 575-582).

Quanto a trabalhos acadêmicos recentes, até o momento identificamos três colaborações especificas sobre o tema, em uma tese de doutoramento em medicina e em duas dissertações de mestrado em história. Um estudo sobre suicídios entre escravos e libertos da Bahia foi apresentado na tese de Ana Maria G.R. Oda (2003), em anexo sobre a história da psicopatologia dos escravos, usando estatísticas policiais e observações das autoridades presentes em relatórios provinciais. Jackson Ferreira, em 2004, concluiu dissertação sobre o suicídio na Bahia do século XIX, da qual resultou ainda a publicação de artigo sobre o suicídio de escravos naquela província. ${ }^{5} \mathrm{O}$ suicídio de cativos no município de Juiz de Fora (MG) foi tratado por Ana Maria Faria Amoglia, em dissertação apresentada em 2006.

Tanto Ana Maria Amoglia (2006) quanto Jackson Ferreira (2004a) usaram informações obtidas de várias fontes, em especial da documentação policial local (inquéritos com depoimentos de testemunhas, correspondências de subdelegados, delegados e chefes de polícia etc.) e de documentos judiciais ligados aos casos de suicídio, além de notícias de jornais e informações de relatórios provinciais. Ferreira (2004b, p.197-234) ressalta a importância dos depoimentos colhidos dos maços policiais, que permitem maior aproximação dos atos suicidas dos escravos conforme vistos pelos diretamente envolvidos, nos testemunhos dos próprios ou de seus vizinhos e parentes, além dos proprietários.

\section{O escravo nos jornais}

Em finais da década de 1930, Gilberto Freyre parece ter sido um dos primeiros a utilizar sistematicamente jornais como fontes para a história da escravidão, em O escravo nos anúncios 
de jornal do tempo do Império (Freyre, 1988, p.243-248), em que analisou material do Rio de Janeiro e de Pernambuco, destacando, entre outros aspectos, as indicações sobre deformidades ou deficiências físicas e marcas de castigos no corpo de escravos anunciados como fugitivos.

Mais recentemente, no livro Retrato em branco e negro, Lilia Moritz Schwarcz (1987) apresentou estudo histórico-antropológico sobre as diversas imagens do negro veiculadas pelas notícias publicadas em três importantes jornais de São Paulo - Correio Paulistano, Província de São Paulo e Redempção - no final do século XIX. As imagens identificadas foram: o negro violento, o negro dependente, o negro feiticeiro, o negro degenerado (em especial, depois da década de 1880) e o negro suicida. Observa a autora que suicídios de escravos ocupavam com freqüência a seção de notícias dos citados periódicos, sobretudo no final da década de 1870, quando apareciam quase diariamente, sendo poucos os casos em que se indicavam dúvidas sobre sua veracidade. Outro aspecto apontado é a preocupação em negar a participação do senhor nessas ações. Com relação às motivações atribuídas aos suicídios dos escravos, Schwarcz analisa que, apesar de muitas vezes não se saber a causa do ato, buscava-se explicá-lo a partir das atitudes da vítima, de seus vícios e maus costumes (como embriaguez); o 'desespero' (por exemplo, quando um escravo em fuga se matava) e a loucura também aparecem como explicações (p.129-130).

\section{O suicídio nas notícias da Gazeta de Campinas}

No presente estudo, consideramos aquilo que as notícias publicadas informam tanto no que tange às visões correntes sobre o fenômeno nelas expresso, quanto no que se refere à descrição dos atos suicidas em seus aspectos numéricos e quantificáveis (freqüência, local de ocorrência, distribuição segundo condição e sexo, meios mais usados, motivações atribuídas). ${ }^{6}$

A Gazeta de Campinas, publicada de outubro de 1869 a setembro de 1890, destaca-se como um dos jornais locais mais duradouros do período. Fundada pelo advogado Francisco Quirino dos Santos, inicialmente tinha circulação semanal, depois bi-semanal (Lapa, 1996); com o tempo, tornou-se jornal com duas folhas (quatro páginas) e, a partir de agosto de 1875, passou a ter circulação diária (GC, 26 ago. 1875).

O jornal era de linha republicana, e de sua redação, além de Quirino, fizeram parte o ainda jovem Campos Salles, futuro presidente da República (1898-1902), e o abolicionista Francisco Glicério, entre outros nomes que se destacariam no Partido Republicano Paulista (PRP), fundado em 1873. Essa vocação política do jornal é indicada por um cronista da cidade: "Os casos de administração geral, provincial e municipal, não raro consistiam objeto de editoriais firmados por um dos três redatores [João Quirino, Jorge Miranda e Campos Salles]" (Brito, 1958, p.120).

Ressalte-se que a Gazeta contava com colaboradores abolicionistas, mas isso não implicava seu alinhamento automático à causa da emancipação imediata ou incondicional dos escravos, pois se sabe que o PRP aglutinava tanto fazendeiros escravistas quanto partidários da abolição, mantendo posição ambígua a respeito do palpitante assunto, observada ainda em outro importante periódico ligado aos republicanos, Província de São Paulo (Toledo, 2003, p.417). 
A Gazeta veiculava informações locais e regionais, além de reproduzir notícias de outros jornais brasileiros e estrangeiros. Era dividida em seções, tais como notícias, anúncios, cartas dos leitores, publicações 'a pedido' e editoriais. Na segunda página, encontrava-se a seção Notícias ou Noticiário, em que eram publicadas principalmente notas curtas sobre acontecimentos relacionados à região de Campinas, bem como avisos sobre espetáculos musicais e teatrais, desastres, nomeações, festas, pessoas importantes que partiam da cidade ou a ela chegavam, gente que "enlouquecera", "atos louváveis" (de filantropia, de libertação de escravos), fatos curiosos etc. Nessa seção encontramos as notícias de suicídio, tanto de escravos quanto de pessoas livres.

Em geral, as notas sobre suicídios de escravos e de pessoas pobres tendem a citar apenas os dados mais importantes do caso. Para os livres pobres (trabalhadores), são fornecidas informações como nome, nacionalidade, ocupação, o local em que foi praticado e o meio utilizado para o suicídio. Quando se tratava de escravos, constavam o nome do senhor e o do escravo, se estava fugido, o local e o meio escolhidos para se matar. As notícias transcritas a seguir ilustram esse estilo sucinto de redação (a ortografia foi atualizada, para facilitar a leitura, exceto nos casos de nomes próprios e topônimos).

\begin{abstract}
'Suicídio' - no dia 11 do corrente, foi encontrado enforcado, já em estado de putrefação adiantada, nas matas da fazenda Taquaral, do sr. capitão Francisco de Paula Bueno, o seu escravo Cypriano, que tinha fugido fazia alguns dias. A autoridade procedeu ao auto de corpo de delito. (GC, 15 fev. 1877)

'Suicídio' - ontem, as 8 e meia horas da manhã, suicidou-se, atirando-se a um poço do quintal da casa de seu senhor, a escrava Francisca, pertencente ao sr. Antonio Joaquim Gomes Tojal. (GC, 6 fev. 1880)

'Suicídio' - anteontem chegou à cidade o cadáver de Felisberto Claro d'Escobar, lavrador do nosso município, propenso, há tempos, a desarranjos mentais, que suicidou-se disparando um tiro de revólver. A polícia tomou logo indagações sobre lamentável ocorrência e procedeu o corpo de delito. (GC, 14 set. 1871)
\end{abstract}

Quando o fato parece ter provocado reprovação, os editores expressam isso; no caso a seguir, enfatizam também que o bom tratamento dado aos escravos por certo senhor nada tem a ver com a ação da mãe que se afogou, levando junto a pequena filha liberta de cinco anos, apenas por perversidade e "nímia malvadeza":

'Suicídio e homicídio' - no dia 7 do corrente, em um sítio do nosso amigo sr. Amador Bueno Machado Florence, uma sua escrava suicidara-se por imersão em tanque, para onde levara perversamente consigo uma filha de cinco anos liberta por aquele nosso amigo; emergiram ambos já cadáveres. Somos perfeitamente informados que só por nímia malvadeza praticara ela aquele tamanho atentado. (GC, 13 fev. 1873)

Já com relação a um caso de suicídio coletivo familiar ocorrido em Atibaia, não aparece espanto nem mesmo condenação explícita, quanto ao fato de escravas matarem-se, supostamente, "por não quererem acompanhar seu novo senhor, fazendeiro", que as viera buscar:

'Suicídio' - lê se no Bragantino: consta-nos que no município do Atibaia, no dia cinco para o seis do andante, suicidaram-se, atirando-se a um tanque quatro escravas, sendo duas mães e duas filhas; tentando suicidarem-se mais três, que foram imediatamente socorridas. Segundo 
informaram-nos foram levadas àquele ato de desespero por não quererem acompanhar seu novo senhor, fazendeiro, residente no município do Amparo, que as veio buscar. Ignoramos os pormenores do fato. (GC, 18 abr. 1879)

Escravos que se suicidavam por ocasião da captura têm o ato atribuído implicitamente ao desejo de não retornar ao cativeiro. Alguns exemplos são o de Philippe, que "estando fugido feriu-se com uma faca, na ocasião de ser preso por ordem de seu senhor", sendo levado ao hospital em grave estado (GC, 9 fev. 1879) e o de Antônio, que tendo fugido da fazenda de seu senhor e sendo encontrado em outra fazenda, ao ver que seria preso "puxou de uma faca que trazia e com ela ofendeu-se gravemente" (3 dez. 1879). Situação semelhante foi a de um escravo que estava fugindo e matou outro escravo que o ia prender, e a seguir tentou matarse "fazendo sobre o pescoço e ventre ferimentos reputados mortais" (23 out. 1879).

No caso a seguir a morte por suicídio aparece como opção à fuga:

'Suicídio' - Ontem de manhã o escravo Manoel, pertencente ao sr. barão de Ibitinga, por motivos que ignoramos, disparou quatro tiros de revólver na cabeça, e vibrou uma terrível navalhada na garganta, pondo assim termo aos seus dias. Manoel tinha dito anteriormente a algumas pessoas que ia suicidar-se ou fugir, e optou pelo mais terrível alvitre. (GC, 8 dez. 1887)

Há várias notícias de suicídios de escravos relacionados a situações de prisão e de condenação judicial (ou possibilidade de condenação) por crimes graves, como homicídio. $\mathrm{O}$ réu Elesbão, escravo preso por assassinar a mulher do feitor, em Rio Claro, pouco antes de entrar em julgamento foi encontrado pelos guardas "caído, de bruços, com a roupa toda ensangüentada". Informa ainda a nota que "Elesbão, sem que os seus companheiros de prisão vissem, quebrara um vidro do lampião e com ele fizera sobre o pescoço uma grande incisão. O ferimento foi julgado mortal. Este incidente fez adiar o seu julgamento" (GC, 12 set. 1882).

O já mencionado escravo Ambrósio, de Campinas, que "se achava cumprindo sentença de ferro ao pescoço por dois homicídios e uma tentativa de homicídio", deu fim à vida com um "profundo golpe sobre o pescoço com uma pequena folha de faca" (GC, 15 out. 1874). Outro caso de suicídio de escravo condenado é o de Adão, que em Mogi-Mirim se enforcou "nas grades internas da prisão, onde se achava, tendo rasgado umas calças para fazer a corda com que estrangulou-se". Adão "no dia anterior tinha sido condenado a galés perpétuas pelo assassinato praticado na pessoa de empregado de seu senhor". Comenta-se: "É inexplicável este procedimento, tendo obtido este escravo a pena que desejava; atribui-se ao desgosto de ter de abandonar os seus companheiros do crime." (3 set. 1879).

Já o escravo João Joaquim retornara havia pouco à fazenda de origem, em Piracicaba, após cumprir na cadeia "sentença de açoites pelo crime de morte praticado em outra escrava", e ali "terminou a existência enforcando-se com um lençol" (GC, 19 maio de 1883).

Quando se trata de notícias de suicídio de pessoas das camadas mais abastadas ou influentes da sociedade, como comerciantes ou fazendeiros, por vezes encontramos diferenças significativas na narrativa das notícias, em que pormenores do caso são citados, os motivos indagados ou comentados, há frases de pesar pela morte do indivíduo e condolências à família. Tal é o caso do "antigo e bem conceituado negociante" Joaquim Isique, natural de Gibraltar, que se matara com um tiro e "segundo declaração que deixou 
do próprio punho pôs termo a seus dias por causa das enfermidades que sofria havia anos, e de que julgava não poder sarar" (GC, 14 jan. 1875). Mas há também notícias breves, como "Suicidou-se no Amparo, disparando um tiro na cabeça o importante fazendeiro Albano Franco de Godoy" (5 mar. 1887).

Outro exemplo pode ser visto na longa nota sobre o suicídio de Epiphanio Gomes de Abreu, ocorrido em 1877. Ele era amigo de "diversos cavalheiros distintos" e deixou um bilhete ao doutor Moraes Salles, conhecido político, em que dizia: "Peço-lhe que não me incrimine se eu cometo um ato de loucura, mas o que fazer? Estou comprometido no meu emprego e vou ficar mal visto". Fica-se sabendo também que o suicida, pouco antes de morrer, "bondosamente" registrara em cartório a paternidade de um afilhado seu, filho de uma escrava. A maior preocupação no texto é defender a honestidade do suicida, cuja prestação de contas na administração do cemitério municipal teria sido injustamente questionada "pela imprensa" (GC, 27 nov. 1877).

Casos ocorridos com pessoas pobres também poderiam ter tratamento mais longo, em especial quando desavenças aparentemente banais davam lugar a atos suicidas. Conta-se que o colono alemão Germano Crabbenhoft, de 59 anos, pretendera abandonar o local de trabalho, mas fora advertido pelo patrão de que "ainda havia café a ser apanhado, não somente nas árvores como no chão". Segundo o jornal, seguiu-se uma discussão, e o colono, "magoado" com as "palavras ásperas" do proprietário, pouco depois da altercação enforcara-se em uma árvore, deixando viúva e filhos menores (GC, 28 set. 1883).

Sobre a relação da Igreja católica com os suicidas, alguns indícios podem ser obtidos das notícias. O já citado "antigo e bem conceituado negociante" estrangeiro Joaquim Isique encontrou as portas da igreja fechadas, sendo alegado que "se não podia encomendar o corpo por constar que era de um protestante" (GC, 14 jan. 1875), contra o que protestava o autor da nota. Já outra notícia parece indicar que a sanção religiosa ao sepultamento de suicidas em solo sagrado estava sendo relaxada, na década de 1880 , pois menciona um local específico para "inumação dos suicidas" na cidade de Bragança Paulista, a "capelinha de Santa Cruz dos enforcados", onde foi enterrada a jovem Antonia Maria das Dores, para ali conduzida "com acompanhamento e música" (6 set. 1882).

Ocasionalmente comentam-se possíveis causas sociais do suicídio, tal como no caso de um moço de 24 anos de idade, que se matou no Recife, deixando este bilhete: "Partidário como sou de Buckner, autor da Força e Matéria, por conseguinte materialista, mato-me. E por quê? Por desejar mais breve que devia ser saber o que se passa lá por cima". Comenta o editor da Gazeta que o bilhete seria prova de que "as faculdades intelectuais do infeliz estavam alteradas, devido isto, sem dúvida, a precoce leitura de livros, para cuja compreensão ainda não tinha o espírito bastante desenvolvido e cultivado" (GC, 11 jun. 1878).

Ainda a respeito da nociva influência de leituras indevidas sobre a ocorrência de suicídios, em 1878 o jornal resume, sem comentar, a proposta dos médicos reunidos na seção de Higiene e Medicina Legal do Congresso Médico de Pisa (Itália), em que pedem aos jornais que não publiquem notícias de suicídio, já que "a imprensa, prestando serviços assinaláveis ao progresso moral e material das nações contribui também para o aumento das mortes voluntárias trazendo em suas colunas as minudências dos suicídios" (GC, 15 nov. 1878). De igual teor é a nota de 16 de outubro de 1883: "Notícias de suicídio - muitos jornais de 
Portugal resolveram não publicar mais as notícias de suicídio, visto que a sua leitura é um perigo e impressionam extraordinariamente as pessoas fracas ...".

Parece, porém, que tais alertas não surtiram efeitos na própria Gazeta de Campinas, que continuou a noticiar suicídios e tentativas, e dar detalhes 'técnicos' que deveriam interessar a seus leitores. Como sobre o suicídio do doutor Luiz Pientznauer, "formado em medicina e lente catedrático da cadeira de anatomia descritiva da Faculdade do Rio de Janeiro", contando que ele "serviu-se para aquele ato de desespero de um bisturi com o qual feriu-se na região supraclavicular direita, o que lhe ocasionou morte instantânea" (GC, 26 set. 1880). Ou sobre "mais um suicídio" na Corte, o do cabo de infantaria Vicente Ferreira de Palma, que "lançou mão de uma carabina Comblain carregada com cartucho embalado, aplicou a boca da arma no estômago e com o auxilio do pé desfechou um tiro, saindo-lhe o projétil na região renal esquerda" (11 jun. 1887).

\section{Sobre registros e notícias de suicídio}

É possível extrair alguns dados quantificáveis do conjunto de notícias do periódico estudado, que complementam aqueles obtidos nas estatísticas policiais publicadas em relatórios provinciais. Advertimos, entretanto, que esses números não devem ser tomados como expressão exata de todos os eventos acontecidos, pois vários fatores devem ter influenciado para que tais casos fossem conhecidos pela polícia ou publicados nas páginas da Gazeta (que, supomos, se valeu muitas vezes das informações policiais).

Em outro trabalho (Oda, Oliveira, 2007, p.10-12), comentamos sobre os cuidados necessários no trabalho com registros produzidos no período imperial, dada a reconhecida precariedade na coleta de informações populacionais básicas, como números de nascimentos e óbitos ou da população escrava. Assim, não nos devemos iludir quanto à exatidão dos números de mortes violentas como os suicídios, mas apenas supor que eles guardam certa proximidade com as ocorrências que deveriam registrar, embora não saibamos em que medida isso aconteceu.

Adicionalmente, há possibilidades específicas de distorção nos registros de mortes de escravos atribuídas a suicídios. Para mais, se homicídios figuraram como suicídios visando proteger os proprietários assassinos, como assinalaram Roger Bastide (1943) e Kátia Mattoso (1988). Também aumentando os números, pode-se supor que a importância das perdas econômicas decorrentes da morte prematura de escravos explicasse a preocupação em registrar seus suicídios com mais atenção. Considere-se ainda que muitos casos de suicídio entre pessoas livres não foram registrados ou noticiados, já que o suicídio era considerado pecado grave, impedindo o enterro em solo sagrado e manchando a reputação do cristão falecido (Mattoso 1988, p.155). Dessa maneira, haveria menor divulgação de suicídios de livres, elevando proporcionalmente sua freqüência entre escravos. De outro lado, diminuindo as estatísticas, mortes acidentais, sobretudo afogamentos, poderiam ter sido suicídios sem testemunhas, como mencionaram vários visitantes do Rio de Janeiro (Karasch, 2001).

Com relação à divulgação de casos de suicídio de escravos, é plausível que ela pudesse ser influenciada por questões políticas, por ter apelo na divulgação da causa abolicionista, já que a denúncia dos horrores da escravidão constituiu importante argumento dos antiescravistas. 


\section{O perfil dos suicidas a partir das notícias da Gazeta}

Condição social e local de ocorrência

Do total de 319 notícias sobre suicídios e tentativas identificadas, 68 se referem a escravos, sendo relativas a 75 eventos ocorridos (já que duas notícias referem-se a mais de um caso), e foram publicadas entre 1872 e 1887. As notícias envolvendo pessoas livres em toda a província de São Paulo foram cem, surgidas entre 1871 e 1887. Foram também identificadas 117 notícias sobre pessoas livres, cujos casos ocorreram em outras províncias brasileiras, havendo ainda 29 casos transcritos de jornais do exterior. A Tabela 1 resume a distribuição dos locais de ocorrência dos eventos noticiados, segundo a condição social.

Tabela 1 - Local de ocorrência e condição, nas notícias de suicídios e tentativas publicadas na Gazeta de Campinas, 1871-1877

\begin{tabular}{lccc|ccr}
\hline Local & \multicolumn{3}{c|}{ Escravos } & \multicolumn{3}{c}{ Livres } \\
\hline & Suicídios & Tentativas & Ambos & Suicídios & Tentativas & Ambos \\
\cline { 2 - 7 } Campinas* & $37(66 \%)$ & $11(57,8 \%)$ & $48(64 \%)$ & $21(12,4 \%)$ & $15(28,3 \%)$ & $36(16,2 \%)$ \\
Outras cidades & $15(26,8 \%)$ & $4(21 \%)$ & $19(25,4 \%)$ & $46(27,2 \%)$ & $18(34 \%)$ & $64(28,8 \%)$ \\
de São Paulo & $1(1,8 \%)$ & - & $1(1,3 \%)$ & $100(59,2 \%)$ & $17(32 \%)$ & $117(52,7 \%)$ \\
Outra província & $3(5,4 \%)$ & $4(21 \%)$ & $7(9,3 \%)$ & $2(1,2 \%)$ & $3(5,7 \%)$ & $5(2,2 \%)$ \\
Não cita & $56(100 \%)$ & $19(100 \%)$ & $175(100 \%)$ & $169(100 \%)$ & $53(100 \%)$ & $222(100 \%)$ \\
\hline Totais & & & & & &
\end{tabular}

*Distribuição dos casos de escravos em Campinas: área rural, 25; área urbana, 12; área indefinida, 11.

Considerando apenas a província de São Paulo, são 67 casos de escravos e 100 de pessoas livres, ou seja, 40\% de escravos e 60\% de livres, em todo o período de 1871 a 1887. Observe-se que, com relação a escravos alforriados, os libertos, foram encontradas apenas duas notas, ambas referentes a Campinas.

Para todos os casos apresentados na Gazeta de Campinas, o número de registros de suicídios efetivados é bem superior ao de tentativas, tanto entre livres quanto entre escravos (cerca de 75\%); quanto a isso, pode-se supor que boa parte das tentativas de suicídio não chegasse ao conhecimento público, mais difícil de acontecer aos casos de morte por suicídio.

\section{Casos de Campinas}

Dos 75 escravos, 48 (64\%) são de Campinas, 19 (25,4\%) de outras cidades da província de São Paulo, não há informação em sete casos $(9,3 \%)$ e apenas um é de outra província, Minas Gerais. Com relação às pessoas livres, dos cem casos noticiados de suicídios e tentativas ocorridos na província de São Paulo, 36 (36\%) se deram em Campinas.

Deve-se ressaltar uma especificidade de Campinas com respeito à população de escravos. Segundo Roberto do Amaral Lapa (1996, p.27), a cidade era conhecida como "a Bastilha negra", tendo na década de 1870 duas vezes mais escravos do que qualquer outro município paulista. Nas palavras desse historiador, Campinas era "uma cidade de negros e pobres que não se mostrava, pois era proibida, mas existia e pulsava escondida, reprimida, pusilânime ou desafiadora" (p.124). Em 1872, o município de Campinas teria cerca de 18 mil pessoas 
livres e 14 mil cativos (Slenes, 2001, p.242, 249), sendo então estes 44\% da população; recorde-se ainda que, com cerca de 32 mil habitantes, o dinâmico município era mais populoso do que a capital paulista.

Foram identificados 84 eventos ocorridos em Campinas, sendo escravos cerca de 57\% dos envolvidos. Assim, mesmo considerando a alta proporção de escravos no município, sua representação é bem maior, no conjunto das notícias publicadas entre 1871 e 1887, do que a das pessoas livres.

\section{Sexo e condição}

Na Tabela 2, vê-se que os homens predominam nos suicídios e nas tentativas, entre escravos e livres, sendo no segundo grupo muito pequena a proporção de mulheres, que se concentram nas tentativas. O pequeno número de casos de mulheres livres pode estar relacionado a sua posição social, que as tornava restritas ao lar e protegidas da exposição pública de seus atos suicidas, em especial nos casos das famílias ditas importantes. Para os escravos, a maior proporção de homens suicidas pode ser, ao menos parcialmente, relacionada ao predomínio masculino nos plantéis da província, inclusive em Campinas (Slenes, 2001, p.249). Ainda assim, a participação de escravas nos suicídios efetivados não é pequena (quase $40 \%$ ).

Tabela 2 - Sexo e condição, nas notícias de suicídios e tentativas publicadas na Gazeta de Campinas, 1871-1887

\begin{tabular}{lccc|crr}
\hline Sexo & \multicolumn{3}{c|}{ Escravos } & \multicolumn{2}{c}{ Livres* } \\
\hline \multirow{2}{*}{ Masculino } & Suicídios & Tentativas & Total & Suicídios & Tentativas & Total \\
\cline { 2 - 7 } Feminino & $34(60,7 \%)$ & $14(73,7 \%)$ & $48(64 \%)$ & $64(95,5 \%)$ & $30(91 \%)$ & $94(94 \%)$ \\
\hline Totais & $22(39,3 \%)$ & $5(26,3 \%)$ & $27(36 \%)$ & $3(4,5 \%)$ & $3(9 \%)$ & $6(6 \%)$ \\
\hline
\end{tabular}

* Computadas apenas as notícias da província de São Paulo.

Meios usados, segundo condição

Os meios mais comumente usados pelos escravos nos suicídios e nas tentativas, tomados conjuntamente, foram enforcamento, afogamento e uso de arma branca; sendo os mesmos meios principais se considerados apenas os suicídios. Nas tentativas, o meio mais comum foi o uso de arma branca, seguido de afogamento. Entre os livres, no conjunto de tentativas de suicídios e também nos consumados, os meios mais freqüentes foram o uso de arma de fogo e enforcamento. Nas tentativas, predominam o uso de arma de fogo e de arma branca e envenenamento. A Tabela 3 resume os dados.

Observa-se que os meios preferidos nos atos suicidas diferem entre livres e escravos. Entre os escravos predomina o enforcamento, seguido de afogamento e uso de arma branca; entre os livres, o uso de arma de fogo e o enforcamento, depois o uso de arma branca na mesma proporção que envenenamento e afogamento. Não se registra caso algum de envenenamento entre os escravos. 
Saulo Veiga Oliveira, Ana Maria Galdini Raimundo Oda

Tabela 3 - Meios utilizados segundo condição, nas notícias de suicídios e tentativas publicadas na Gazeta de Campinas, 1871-1887

\begin{tabular}{|c|c|c|c|c|c|c|}
\hline \multirow[t]{2}{*}{ Meio utilizado } & \multicolumn{3}{|c|}{ Escravos } & \multicolumn{3}{|c|}{ Livres* } \\
\hline & Suicídios & Tentativas & Ambos & Suicídios & Tentativas & Ambos \\
\hline Enforcamento & $23(41,1 \%)$ & $1(5,2 \%)$ & $24(32 \%)$ & $21(31,3 \%)$ & $3(9,1 \%)$ & $24(24 \%)$ \\
\hline Afogamento & $18(32,1 \%)$ & $5(26,4 \%)$ & $23(30,7 \%)$ & $6(8,9 \%)$ & $2(6,1 \%)$ & $8(8 \%)$ \\
\hline Arma branca & $8(14,3 \%)$ & $9(47,4 \%)$ & $17(22,6 \%)$ & $2(2,9 \%)$ & $7(21,2 \%)$ & $9(9 \%)$ \\
\hline Arma de fogo & $4(7,1 \%)$ & - & $4(5,3 \%)$ & $26(38,8 \%)$ & $11(33,3 \%)$ & $37(37 \%)$ \\
\hline $\begin{array}{l}\text { Instrumento } \\
\text { perfurante }\end{array}$ & $1(1,8 \%)$ & $1(5,2 \%)$ & $2(2,7 \%)$ & $1(1,5 \%)$ & $3(9,1 \%)$ & $4(4 \%)$ \\
\hline Envenenamento & - & - & - & $4(5,9 \%)$ & $5(15,1 \%)$ & $9(9 \%)$ \\
\hline Não cita & $1(1,8 \%)$ & $1(5,2 \%)$ & $2(2,7 \%)$ & $6(8,9 \%)$ & - & $6(6 \%)$ \\
\hline Outros $^{a, b}$ & $1(1,8 \%)$ & $2(10,6 \%)$ & $3(4 \%)$ & $1(1,5 \%)$ & $2(6,1 \%)$ & $3(3 \%)$ \\
\hline Totais & $56(100 \%)$ & 19 (100\%) & 75 (100\%) & 67 (100\%) & $33(100 \%)$ & $100(100 \%)$ \\
\hline
\end{tabular}

* Computadas apenas as notícias da província de São Paulo.

a) Escravos: suicídio - um esmagamento por locomotiva; tentativas - dois se colocaram nos trilhos do trem.

b) Livres: suicídio - um esmagamento por locomotiva; tentativas - dois casos de uso de dois meios, arma fogo e arma branca; dois por precipitação de locais altos.

Os meios empregados pelos suicidas podem refletir maior ou menor determinação de morrer e ter sido escolhidos conforme sua letalidade presumida (muito alta no caso de enforcamento, por exemplo), mas certamente considerando sua disponibilidade.

Os poucos casos de escolha de arma de fogo parecem estar associados ao acesso a esse meio, muito restrito no caso de escravos; já o enforcamento poderia ser executado de várias maneiras, usando objetos e circunstâncias disponíveis, tal como descrito nas notícias (com cordas, peças de roupa, em árvores, nas grades da cadeia etc.). De forma semelhante, instrumentos cortantes de uso cotidiano, como facas de cozinha, canivetes ou navalhas, poderiam ser obtidos pelos escravos sem muitas dificuldades. O afogamento é o segundo meio preferido pelos escravos, aparecendo em quarto lugar entre os livres; também aqui, a disponibilidade do meio deve ser considerada, já que poços, rios e tanques abundavam.

Além disso, vimos que o afogamento e o enforcamento aparecem, nos relatos dos viajantes, relacionados a representações religiosas de origem africana, por serem métodos que facilitariam o retorno à África através da reencarnação (Bastide, 1943, p.2). Mary Karasch (2001) levantou literatura antropológica indicando a existência dessas crenças especialmente entre os designados 'congos' (vindos do centro-oeste africano), que acreditavam poder se reunir aos ancestrais, após a morte, atravessando a água (Calunga) e também que seus ancestrais viviam nas florestas, no ar e nas águas (p.418, 578).

Para a Bahia, onde no século XIX predominaram os negros vindos de variados grupos étnicos da África Ocidental, Ferreira (2004b, p.228) observou que entre 1850 e 1888 o percentual de africanos suicidas era muito significativo, e eles preferiam o enforcamento e o afogamento, ao passo que os cativos brasileiros optavam pelo envenenamento. Considerou também a possibilidade da relação entre as escolhas e as crenças religiosas citadas, alertando, porém, contra o uso exagerado dessa explicação. 
No caso de São Paulo, não foram encontradas referências à associação entre o meio escolhido e crenças religiosas. Observe-se que as notícias da Gazeta e os relatórios da província não indicam quantos suicidas eram nascidos na África, mas podemos supor que houvesse alguns, já que, segundo o Censo de 1872, haveria $8 \%$ de africanos entre os escravos da província (cf. Alencastro, 2001, p.484).

Sabe-se que boa parte dos africanos trazidos como escravos para o Sudeste veio de grupos da África Central (Angola e baixo rio Zaire) e que suas culturas tinham muitas afinidades, apesar da diversidade étnica. Observa Slenes (2001, p.250) que a constituição da família escrava serviu como facilitadora da junção dessas culturas centro-africanas, a que se acrescentariam valores e tradições trazidos pelos escravos vindos depois de 1850, principalmente do Nordeste. Assim, mesmo para os escravos nascidos no Brasil, os valores culturais dos avós africanos continuariam muito presentes (p.282), dinamicamente ressignificados no contexto brasileiro.

Desta forma, parece-nos que crenças africanas podem ser consideradas relevantes na escolha dos métodos suicidas pelos escravos - enforcamento (homens) e afogamento (mulheres) - tanto quanto sua disponibilidade ou facilidade de acesso.

Motivações atribuídas, segundo condição

Em geral, as motivações atribuídas aos atos suicidas nas notícias são pouco precisas, quando existem. Em cerca de metade dos casos, sejam estes referentes a escravos ou livres, elas não são citadas ou são ignoradas. Nos relatórios provinciais, com informações ainda mais esporádicas e genéricas, a maioria dos casos de escravos é atribuída a "desgostos do cativeiro", clichê recorrente nos discursos sobre os atos suicidas dos cativos. Nesse sentido, deve-se considerar que as atribuições de motivos tanto podem ter-se baseado em informações obtidas dos inquéritos policiais, mais ou menos fidedignas, quanto ser mera suposição do autor das notas, que talvez recorresse a visões estereotipadas sobre as causas de suicídios.

Considerando-se os 42 casos (56\%) em que a citação dos supostos motivos existe (para suicídios e tentativas em conjunto) vê-se que, entre os escravos, os casos ocorridos com presos ou relacionados à prisão somam nove referências (condenado por homicídio; logo após cometer homicídio; preso já condenado; preso aguardando julgamento; recém-saído da prisão); e com acusados de crimes como furto e homicídio são três. São quase todos homens (apenas uma mulher, acusada de furto). Esse relacionamento de motivações a crimes pode prender-se aos pesados castigos físicos dados aos escravos condenados, como a pena de açoites, e ainda à possibilidade de condenação a trabalhos forçados (pena de galés), como verificado em alguns dos casos que citamos. Ou, ainda, a ameaças de castigos (dos senhores ou na prisão), nos casos de simples suspeitas de crime. Como vimos, castigos excessivos e medo de castigos como causas de suicídios entre escravos são mencionados já nos relatos dos viajantes e na literatura subseqüente. Casos de escravos capturados somam quatro, também todos homens, parecendo clara a opção pela morte diante da iminência do retorno ao cativeiro.

Outro conjunto de casos (dez) diz respeito a situações relacionadas à venda (nove de resistência a passar para outro dono e um de desejo de acompanhar companheiros vendidos). Observe-se que aí se incluem os citados sete suicídios ocorridos em Atibaia, sendo quatro 
na mesma família. Nesses casos, em que há apenas um homem, a procura da morte surge como forma de recusa à violência da mudança forçada, podendo-se supor o desejo de manter vínculos locais familiares e afetivos.

De forma similar, para os casos da Bahia, Jackson Ferreira (2004b, p.210) apontou que os motivos diretamente vinculáveis à escravidão (captura após fuga, castigo e ameaça de venda) foram responsáveis por metade das possíveis motivações dos 87 suicídios em que se pôde obter essa informação.

Os outros motivos mencionados nas notícias da Gazeta são transtornos mentais em sentido amplo (três casos): "acesso de loucura", "momento de desvario" e por estar "caduca"; dois casos relacionados a homicídio passional (amoroso); e um a embriaguez; em um caso fica-se em dúvida se a "malvadeza" é considerada causa apenas do filicídio ou também do suicídio da escrava.

Para 44 casos de livres, nos suicídios e tentativas juntos, as motivações mais citadas são desarranjo ou alienação mental (18), relacionadas à desonra, injustiça e ofensa (seis), decorrentes de paixão amorosa, ciúmes ou briga conjugal (seis) e após homicídio passional da ex-esposa (três). Seguem-se variadas justificativas, como problemas comerciais ou financeiros (dois), "aborrecimento da vida" (dois), doença incurável (dois), "desvio da imaginação" (um), "sentimentos particulares" (um), "motivo de família" (um), "ao ver a mãe morta" (um) e "por estar embriagado" (um).

Assinale-se a atribuição diferenciada de motivações dos atos suicidas para livres e escravos, sendo que a imputação a transtornos mentais predomina entre os livres e é muito pouco citada quanto a escravos. Para os livres, além da alienação mental, os outros motivos mais comumente atribuídos poderiam ser qualificados como 'passionais', ou seja, relacionados a valores morais, afetos em geral e paixão amorosa contrariada. Dessa forma, causas que chamaríamos de psicopatológicas são ligadas muito mais aos suicídios dos livres do que aos dos cativos, o que pode refletir não só a predominância de suicídios ligados à situação do cativeiro, mas ainda a visão de que escravos (ou negros) seriam moralmente diferentes das pessoas da classe senhorial.

A título de comparação, vale destacar a diferença na proporção dos casos atribuídos à alienação mental, na citada pesquisa de Ferreira (2004b, p.208) sobre a Bahia, e a similaridade das motivações ligadas ao cativeiro. Para 87 suicídios de escravos, os motivos mais comuns foram: alienação mental (22; 25,3\%), situação de captura $(21 ; 24,2 \%)$, relacionado a castigos $(16 ; 18,4 \%)$, a crimes $(12 ; 13,8 \%)$, a vendas (seis; $6,9 \%)$ e a situações amorosas (seis; 6,9\%).

\section{Na província de São Paulo, os escravos se matavam mais do que as pessoas livres?}

Entre 1870 e 1887, a proporção dos casos de suicídios de escravos noticiados foi de cerca de $43 \%$ e a dos registrados nas estatísticas policiais dos relatórios provinciais, 50\%.

Segundo dados do Censo de 1872, a província de São Paulo tinha pouco mais de 835 mil habitantes, sendo escravos perto de 155 mil (cf. Alencastro, 2001, p.479), ou seja, os escravos representavam cerca de $19 \%$ da população. Considerando as informações vindas das notícias (suicídios e tentativas em conjunto), quando se toma o total de 59 casos da 
província de São Paulo entre 1871 e 1879, 39 são escravos (66\%) e 20 livres (34\%) - portanto, o percentual de escravos nas notícias de suicídio é muito maior do que sua presença na população estimada para 1872 (Oliveira, 2007, p.144).

A população escrava da província decresceu nos últimos anos da década de 1880, em razão do crescente número de alforrias e da cessação do tráfico interprovincial. Tomando duas das várias e díspares estimativas existentes, consideremos que ela estivesse perto de cem mil cativos em 1887 (Fausto, 2001, p.201), sendo a população total pouco mais de um milhão de pessoas (Carneiro, 1986, p.235), e teremos proporção em torno de 10\% de escravos. Ainda que os números sejam imprecisos, pode-se observar que a redução relativa na população provincial certamente não foi tão acentuada quanto aquela observada nas 67 notícias de suicídio da Gazeta, onde entre 1880 e 1887 aparecem 17 casos de escravos (26\%) e 49 de livres (74\%) (Oliveira, 2007, p.144).

Considerando apenas os casos consumados segundo os registros da Gazeta, as taxas médias anuais de suicídio, entre 1870 e 1879 , seriam de 3,2 por cem mil entre escravos e 0,3 por cem mil entre pessoas livres; entre 1880 e 1887, de 2,8 por cem mil entre escravos e de 0,8 por cem mil entre livres. Já de acordo com as estatísticas oficiais, no primeiro período as taxas seriam de 6 suicídios por cem mil escravos e 1,6 por cem mil livres e no segundo, de 4,6 por cem mil entre escravos e de 0,3 por cem mil entre livres.

Em resumo, o que as informações que temos permitem afirmar é que a proporção de escravos nos registros de suicídio compilados é maior do que seu percentual na população geral estimada, o que pode apenas indicar uma resposta positiva à questão formulada.

\section{Possíveis significados da redução dos casos noticiados}

As notícias de suicídios de escravos na Gazeta diminuem, em especial depois de 1885, mas é difícil afirmar que isso reflita diretamente uma efetiva diminuição dos casos ocorridos; pode-se apenas apontar que as notícias acompanham a tendência dos registros policiais da província.

Bastide (1943, p.8) atribuiu a diminuição observada nos registros policiais de suicídios de escravos da província de São Paulo, nos anos próximos a 1888, à crescente propagação das idéias abolicionistas e às perspectivas concretas de obtenção de liberdade, que teriam reduzido o número de casos. O mesmo pensa Venâncio (1990, p.83) sobre os registros da Corte. Para o caso da Bahia, em que constatou a mesma redução, Ferreira (2004b, p.207) pondera que isso pode ser, em parte, devido à diminuição da população escrava, embora às vésperas da abolição o contingente escravo fosse ali ainda significativo.

São explicações plausíveis, que se poderiam aplicar também à província de São Paulo. Porém, além de supor que os suicídios de escravos diminuíram diante da perspectiva de liberdade (pelo menos, os diretamente ligados ao estado de cativeiro), é possível imaginar se, na conturbada década de 1880 , as autoridades não estariam mais preocupadas com questões referentes à manutenção da ordem do que com o registro de suicídios de cativos, o mesmo ocorrendo com o espaço dado às notas de seus suicídios na imprensa. Talvez o foco das notícias se tenha dirigido às fugas coletivas e às rebeliões de escravos e ainda à radicalização do movimento abolicionista, assim como, nessa época, em seus relatórios os 
presidentes e os chefes de polícia se ocuparam sobretudo da generalização do protesto escravo nas fazendas paulistas (Azevedo, 1987, p.210).

\section{Considerações finais}

A história social da escravidão sublinha o caráter humano de escravos e senhores, sua ação como sujeitos históricos, sem evidentemente desconsiderar a desigualdade de posições sociais e a violência inerente à escravidão. Nesse sentido, o suicídio cativo pode ser visto também, mas jamais unicamente, como forma de protesto ou fuga da situação de cativeiro, sempre considerando a complexidade da experiência da escravidão e a capacidade humana de descobrir formas de viver em condições adversas.

Assim, não nos parece justificável que o fenômeno do suicídio entre escravos no Brasil seja tomado como auto-explicável por sua desfavorável condição. Cremos que os atos suicidas são manifestações humanas extremas que não podem ser reduzidas a explicação única, seja ela de caráter sociológico, antropológico ou psicopatológico, e que devem ser sempre referidas aos contextos históricos em que se dão. Esperamos que nosso trabalho permita vislumbrar a variedade das situações em que ocorreram esses atos - bem como as possíveis distorções no seu registro - e que ele contribua para desfazer explicações simplificadoras, que de certa forma repetem a expressão-clichê recorrente nos documentos oficiais, a que afirmava serem os suicídios de escravos apenas e obviamente decorrentes de "desgostos provenientes do cativeiro".

\section{NOTAS}

\footnotetext{
${ }^{1}$ Doravante adotaremos as iniciais GC para designar este periódico.
}

${ }^{2}$ Este artigo deriva da dissertação de mestrado de Saulo Veiga Oliveira, Suicídios de escravos em Campinas e na província de São Paulo (1870-1888), defendida em agosto de 2007 sob orientação de Ana Maria G.R. Oda. O pesquisador contou com bolsa da Capes, e o estudo desenvolveu-se no âmbito do projeto Dos Desgostos Provenientes do Cativeiro: Uma História da Psicopatologia dos Escravos Brasileiros no século XIX, financiado pela Fundação de Amparo à Pesquisa do Estado de São Paulo (Fapesp, processo 04/ 00442-4).

${ }^{3}$ Menções ao banzo e aos suicídios de escravos (freqüência, métodos usados, motivações etc.) podem ser encontradas nas obras do bávaro Carl F. von Martius (1939, p.29-33), dos franceses Joseph François Sigaud (1844, p.126-142) e Jean-Baptiste Debret (1940, v.2, p.186) e do inglês Henry Koster (1978, p.372433). Sobre os relatos de outros viajantes sobre o assunto, ver ainda Karasch (2001, p.415-420) e Bastide (1943, p.2-6).

${ }^{4}$ Excertos das duas versões da memória de Luis Antonio de Oliveira Mendes, com destaque para a descrição do banzo, foram republicados na Revista Latinoamericana de Psicopatologia Fundamental, v.10, n.2, 2007, p.362-376. Sobre o ensaio de Oliveira Mendes, ver Oda (2007).

${ }^{5}$ Destacamos o trabalho de pesquisa realizado por Jackson Ferreira (2004a; 2004b), bem como a competente discussão sobre os sentidos do suicídio cativo na Bahia. Ressalte-se que Ferreira encontrou, na documentação policial, algo muito raro: o bilhete do mulato Timóteo, jovem escravo que se matou em 1861, na cidade de Salvador (p.216 e seg.).

${ }^{6} \mathrm{O}$ jornal foi pesquisado em edições de 18 anos consecutivos, de 1870 a 1887 (exceto 1881, ausente no arquivo). O trabalho de levantamento e cópia das notícias da Gazeta de Campinas contou com a importante colaboração de Luciana Piedemonte e, posteriormente, de Beatriz Gabrinha, ambas alunas de graduação em medicina da Faculdade de Ciências Médicas da Unicamp e participantes de projeto de iniciação científica. 


\section{FONTES E REFERÊNCIAS BIBLIOGRÁFICAS}

\section{Fontes}

Gazeta de Campinas. 1870 a 1887 (exceto 1881). Periódico microfilmado. (Arquivo Edgard Leuenroth, Instituto de Filosofia e Ciências Humanas da Unicamp).

Datas de publicação das notícias citadas: 14 set. $1871 ; 13$ fev. 1873 , 8 jun. $1873 ; 15$ out. $1874 ; 14$ jan. 1875, 26 ago. 1875, 1 dez. 1875; 13 dez. 1876; 15 fev. 1877, 22 mar. 1877, 5 out. 1877, 27 nov. 1877 ; 11 jun. 1878, 15 nov. 1878; 9 fev. 1879, 18 abr. 1879, 3 set. 1879, 23 out. 1879, 18 nov. 1879, 3 dez. 1879; 6 fev. 1880, 26 set. 1880; 19 maio 1883, 21 jul. 1883, 21 ago. 1883, 6 set. 1883,12 set. $1883 ; 28$ set. 1883,16 out. $1883 ; 23$ abr. 1884; 5 mar. 1887, 11 jun. 1887, 5 jul. 1887, 8 dez. 1887.

\section{Referências bibliográficas}

ALENCASTRO, Luiz Felipe de (Org.).

História da vida privada no Brasil. v.2. São Paulo: Companhia das Letras. 2001.

AMOGLIA, Ana Maria Faria.

Um ar de liberdade: o suicídio de escravos no município de Juiz de Fora (1830-1888).

Dissertação (Mestrado) - Universidade Federal Fluminense, Niterói. 2006.

AZEVEDO, Célia Marinho de.

Onda negra, medo branco: o negro no imaginário das elites, século XIX. São Paulo: Paz e Terra. 1987.

BASTIDE, Roger.

O candomblé da Bahia: rito nagô. Trad. Maria Isaura Pereira de Queiroz. Revisão técnica Reginaldo Prandi. São Paulo: Companhia das Letras. Primeira edição do original francês, Le candomblé de Bahia: rite nagô, 1958. 2001.

BASTIDE, Roger.

Os suicídios em São Paulo, segundo a cor. Boletim de Sociologia da Universidade de São Paulo, São Paulo, USP, n.71, p.1-49. 1943.

BRITO, Jolumá.

História da cidade de Campinas. Campinas: s.n. 1958.

DEBRET, Jean-Baptiste.

Viagem pitoresca e histórica ao Brasil. Trad., notas Sérgio Milliet. São Paulo: Livraria Martins. Título original, Voyage pittoresque et historique au Brésil, 1834-1839. 1940.

CARNEIRO, Glauco.

O poder da misericórdia: a Irmandade da Santa Casa na história social e política da cidade de
São Paulo (província). Estatísticas policiais dos relatórios dos presidentes de província, publicadas em 1871, 1873, 1874, 1878, 1880, 1881, 1882, 1884, 1886 e 1888. Disponível em: http:// www.crl.edu/content/brazil/sao.htm. Acesso em: 1 jul. 2007.

São Paulo (província). Relatório do chefe de polícia Joaquim José do Amaral, juiz de direito. Anexo ao Relatório apresentado à Assembléia Legislativa Provincial de São Paulo pelo presidente da província, Dr João Theodoro Xavier, em 5 de fevereiro de 1874. São Paulo, Tipografia Americana, 1874. Disponível em: http:// brazil.crl.edu/bsd/bsd/1015/index.html. Acesso em: 1 jul. 2007.

São Paulo, 1560/1985. São Paulo: Press Grafic, 1986.

FAUSTO, Boris

História do Brasil. São Paulo: Edusp/FDE. 2001.

FERREIRA, Jackson André da Silva.

Loucos e pecadores: suicídio na Bahia do século XIX. Dissertação (Mestrado) - Universidade Federal da Bahia, Salvador. 2004a.

FERREIRA, Jackson André da Silva.

'Por hoje se acaba a lida': suicídio escravo na Bahia (1850-1888). Afro-Ásia, Salvador, v.31, p.197-234. 2004b.

FREYRE, Gilberto.

Deformações de corpo nos negros fugidos. In: Novos estudos afro-brasileiros: trabalhos apresentados ao 1을 Congresso Afro-Brasileiro realizado no Recife, em 1934. Prefácio Artur Ramos. Recife: Massangana. p.243-248. Facsímile de edição de 1937, da editora Civilização Brasileira. 1988.

GOULART, José Alípio.

Da fuga ao suicídio: aspectos da rebeldia do escravo no Brasil. Rio de Janeiro: Conquista/ INL. 1972.

KARASCH, Mary C.

A vida dos escravos no Rio de Janeiro (1805-1850). São Paulo: Companhia das Letras. 2001.

KOSTER, Henry.

Viagens ao Nordeste do Brasil. Trad., prefácio Luís da Câmara Cascudo. Recife: Secretaria de Educação e Cultura. Título original, Travels in Brazil, 1816. 1978. 
LAPA, José Roberto do Amaral.

A cidade, os cantos e os antros: Campinas, 18501900. São Paulo: Editora da Universidade de São Paulo. 1996.

MATTOSO, Kátia Queiroz.

Ser escravo no Brasil. São Paulo: Brasiliense. 1988.

MOURA, Clóvis.

Dicionário da escravidão negra no Brasil.

São Paulo: Edusp. 2004.

ODA, Ana Maria Galdini Raimundo. O banzo e outros males: o páthos dos negros escravos na Memória de Oliveira Mendes. Revista Latinoamericana de Psicopatologia Fundamental, São Paulo, v.10, n.2, p.346-361. 2007.

ODA, Ana Maria Galdini Raimundo. Esboço de uma história da psicopatologia dos escravos brasileiros. In Oda, Ana Maria Galdini Raimundo. Alienação mental e raça: a psicopatologia comparada dos negros e mestiços brasileiros na obra de Raimundo Nina Rodrigues. Tese (Doutorado) - Universidade Estadual de Campinas, Campinas. p.391-428. 2003.

ODA, Ana Maria Galdini Raimundo; OLIVEIRA, Saulo Veiga.

Registros de suicídios entre escravos em São Paulo e na Bahia (1847-1888): notas de pesquisa. Trabalho apresentado no 3. Encontro Escravidão e Liberdade no Brasil Meridional, 24 maio 2007. Florianópolis. 2007. Disponível em: http://www.labhstc.ufsc.br/pdf2007/ 6.6.pdf. Acesso em: 1 jul. 2007.

OLIVEIRA, Saulo Veiga.

Suicídios de escravos em Campinas e na província de São Paulo (1870-1888). Dissertação (Mestrado) - Universidade Estadual de Campinas, Campinas, 2007.

OLIVEIRA MENDES, Luis Antonio de. Memória a respeito dos escravos e tráfico da escravatura entre a Costa d'África e o Brazil: apresentada à Real Academia das Ciências de Lisboa, 1793. Prefácio José Capela. Porto: Publicações Escorpião. 1977.
OLIVEIRA MENDES, Luis Antonio de Oliveira. Discurso acadêmico ao programa... In: Carreira, Antônio. As companhias pombalinas de Grão-Pará e Maranhão e Pernambuco e Paraíba. Lisboa: Editorial Presença. 1. ed., 1969. Apenso documental (documento n. 11), p. 364-420, transcrito de Memórias económicas da Academia Real das Sciências de Lisboa, tomo IV, Lisboa, Tipografia da Academia, 1812, p.1-82. 1983.

PÔRTO, Ângela.

O sistema de saúde do escravo no Brasil do século XIX: doenças, instituiçõos e práticas terapêuticas. História, Ciências, Saúde Manguinhos, Rio de Janeiro, v.13, n.4, p.10191027. dez. 2006.

\section{SCHWARCZ, Lilia Moritz.}

Retrato em branco e negro: jornal, escravos e cidadãos em São Paulo no final do século XIX. São Paulo: Companhia das Letras. 1987.

SIGAUD, Joseph François Xavier.

Du climat et des maladies du Brésil. Paris: Fortin, Mason et C. 1844.

SLENES, Robert Andrew Wayne.

Senhores e subalternos no oeste paulista. In: Alencastro, Luiz Felipe de (Org.).

História da vida privada no Brasil. v.2. São Paulo: Companhia das Letras. 2001. p.234-290.

TOLEDO, Roberto Pompeu de. A capital da solidão: uma história de São Paulo das origens até 1900. Rio de Janeiro: Objetiva. 2003.

VENÂNCIO, Renato Pinto.

A última fuga: suicídio de escravos no Rio de Janeiro (1870-1888). LPH - Revista de História, Mariana, v.1, n.1, p.80-89. 1990.

\section{VON MARTIUS, Carl F.P.}

Natureza, doenças, medicina e remédios dos índios brasileiros. Trad., prefácio Pirajá da Silva. São Paulo: Companhia Editora Nacional. Título original, Das Naturell, die Krankheiten, das Arztthum und die Heilmittel der Uberwohner Brasiliens, 1844. 1939.

\section{$\rightarrow \rightarrow \gg<<<$}

